Proc. Estonian Acad. Sci. Eng., 2005, 11, 2, 140-153

\title{
Particle dynamics and mixing in an oscillating viscous vortex pair
}

\author{
Felix Kaplanski ${ }^{a}$, Sergei Sazhin ${ }^{\mathrm{b}}$ and Ylo Rudi ${ }^{\mathrm{a}}$ \\ a Laboratory of Multiphase Media Physics, Tallinn University of Technology, Akadeemia tee 23A, \\ 12618 Tallinn, Estonia; fkaplan@eeri.ee \\ b School of Engineering, Faculty of Science and Engineering, The University of Brighton, Brighton \\ BN2 4GJ, UK
}

Received 15 September 2004, in revised form 6 April 2005

\begin{abstract}
A model of a viscous vortex pair, based on a solution of the Stokes equation, is applied for studying particle dynamics and mixing in vortex-pair-like structures. The perturbed flow field and dynamics of small spherical particles, contained in this flow, are studied on the basis of this solution. The particle-path equations and well-established techniques, such as computing of Poincaré maps, is used. It is shown that the flow inside the vortex pair can behave chaotically when a relatively thick pair (core size of the pair comparable with its radius) is under the influence of a periodic perturbation. This is expected to lead to better mixing of the fluid. However, an increase of the perturbation frequency causes the appearance of regions where a bounded quasi-periodic motion occurs. These regions behave like barriers in the phase space, reducing mixing and transport processes in the fluid. Introduction of the perturbation causes changes in the trajectories of the spherical aerosol-type particles. For a certain range of Stokes numbers $(S t<10)$, long-term accumulation inside the vortex pair is observed for these particles, while the same particles in the unperturbed flow are forced out of the pair into the ambient flow.
\end{abstract}

Key words: viscous flow, Stokes equation, vortices, vortex pair.

\section{INTRODUCTION}

It is known that particle motion is generally more complex than the fluid dynamics. For example, while the motion of three-point vortices in an unbounded domain is integrable, motion of fluid elements and particles in this flow can be chaotic $\left[{ }^{1}\right]$. This is expected to lead to flow-particle mixing and it has stimulated a number of studies of the kinematics of mixing in several types of flows, e.g. in the flow due to two blinking vortices $\left[{ }^{2}\right]$, in the two-dimensional flow, generated 
by time-periodic motion of eccentric cylinders $\left[{ }^{3}\right]$, and in the flow, generated at opposite sides of the rectangular cavity $\left.{ }^{4}\right]$. Most of these studies were focused on two-dimensional time-periodic motions. In two dimensions, equations for the trajectories of fluid particles are identical with those describing a Hamiltonian system, and the fluid mixing follows from the chaotic behaviour of this system.

Vortex ring and vortex pair are fundamental types of flow, which are relevant to a wide variety of applications, including the oscillatory flows in wavy-walled tubes and trailing vortices. Also, a typical fuel injection process in internal combustion engines is accompanied by the development of a fountain-like structure, consisting of a spray jet and a vortex ring [ $\left.{ }^{5}\right]$.

The transport and mixing in the flow velocity field, induced by the inviscid vortex pair under the influence of time-periodic perturbations, was investigated by Rom-Kedar et al. $\left[{ }^{6}\right]$ using analytical techniques. Ottino $\left[{ }^{7}\right]$ and Tsega et al. $\left[{ }^{8}\right]$ studied the transport and mixing in the perturbed "Kelvin cat eyes" flow numerically. They showed that the influence of time-periodic perturbations could generate the "extent of chaos". In $\left[{ }^{6}\right]$ it was shown that such phenomenon also occurs for particles in the perturbed inviscid vortex pair. In $\left.{ }^{8}\right]$, not only the stochastic behaviour of the underlying perturbed "Kelvin cat eyes" flow was studied but it was also investigated how this stochastic behaviour can affect the dynamics of particles in the "aerosol" and "bubble" ranges. These studies were motivated by the hypothesis that even simple two-dimensional time-dependent flows with a cellular flow field structure can show a behaviour, similar to real fully turbulent eddies of small-scale mixing. Therefore studies of such flows may highlight features that arise in more complicated turbulent flows.

For the viscous vortex ring flow, the dimensional analysis and the condition of conservation of the impulse of vorticity determine a self-similar vorticity distribution in the long-time limit $\left[{ }^{9}\right]$. An analogue of this result for a vortex pair was discussed in $\left[{ }^{10}\right]$. Attempts to generalize the self-similar vorticity distribution to a wider range of times for vortex rings and pairs were made by Kambe and Oshima $\left[{ }^{11}\right]$ and Cantwell and Rott $\left[{ }^{10}\right]$. Both papers took into account effects of non-linear convection, but results led to the non-uniform validity of the solutions.

Another solution for the viscous vortex ring problem in the form of vorticity distribution was proposed in $\left[^{12,13}\right]$. Later this solution was interpreted as the first order term of the expansion in powers of the time-dependent Reynolds numbers $R e=\varsigma_{0} L^{2} / v$, where $\varsigma_{0}$ is the time-dependent scale of the vorticity, $L$ is the diffusivity scale of the ring's core and $v$ is the kinematic viscosity. The value of $L$ was shown to be equal to $(2 v t)^{1 / 2}$ and it was identified as the ring's inner radius $\left[{ }^{14,15}\right]$. In this case a more general similarity transformation of the governing equations was applied and a new parameter, $\tau=R_{0} / L$, was introduced; here $R_{0}$ is the initial outer radius of the vortex ring (Fig. 1). This approach makes it possible to construct a model of the viscous vortex ring, in which the vorticity distribution reduces to the result obtained in $\left[^{9}\right]$ for $t \rightarrow \infty$ and tends to a circular vortex line for $t \rightarrow 0\left[{ }^{16}\right]$. The latter model represents an approximation of the 


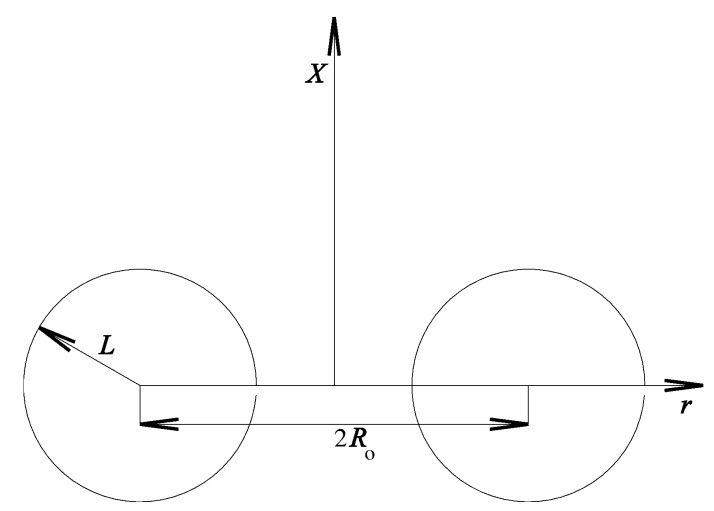

Fig. 1. A schematic presentation of the cross-section of a vortex pair.

vortex ring properties for the time of its evolution. The analogue of this solution for a vortex pair was found in $\left[^{10,15}\right]$. It represents the superposition of two equal but counter-rotating Lamb-Oseen vortices. These structures can be classified in terms of the parameter $\tau$. Members of this class have cores, which diminish with the increasing of $\tau$. In this paper, the model of the viscous vortex pair is used as a simple flow model for studying particle dynamics and mixing in ring-like vortex structures.

The objective of the paper is twofold. First, we analyse fluid motion in an oscillating vortex pair on the basis of the asymptotic solution for this pair, taking into account the effect of viscosity. It avoids difficulties that arise in the numerical calculations caused by the singularity of the solution for an inviscid vortex pair $\left.{ }^{6}\right]$. Invariant manifolds under the influence of a periodic perturbation are studied using the Poincaré surface sections.

Second, we calculate trajectories of aerosol-type particles, inserted in the oscillating vortex pair, using the Lagrangian approach. The motion of these particles is expected to approximate more accurately real transport processes compared with fluid particles.

The plan of the paper is the following. In Sections 2 and 3, the fluid flow in the perturbed viscous vortex pair is analysed with emphasis on the mixing. In Section 4, the motion of small spherical particles, inserted in the vortex pair flow, is considered. The main results of the paper are summarized in Section 5 .

\section{MODEL OF A VISCOUS VORTEX PAIR}

In the limit of small $R e$, the evolution of a viscous vortex pair can be described, based on the solution for the vorticity distribution $\left[{ }^{15}\right]$, as 


$$
\begin{aligned}
\Omega= & \frac{M}{4 \pi v t R_{0}}\left[\exp \left(-\frac{\left(x-x_{0}\right)^{2}+\left(r-R_{0}\right)^{2}}{4 v t}\right)\right. \\
& \left.-\exp \left(-\frac{\left(x-x_{0}\right)^{2}+\left(r+R_{0}\right)^{2}}{4 v t}\right)\right] \\
= & \frac{M}{2 \pi v t R_{0}} \exp \left(-\frac{\left(x-x_{0}\right)^{2}+r^{2}+R_{0}^{2}}{4 v t}\right) \sinh \left(\frac{r R_{0}}{2 v t}\right),
\end{aligned}
$$

where $2 R_{0}$ is the initial distance between the vortices (Fig. 1) located at the point $x_{0}(t), r$ and $x$ are the longitudinal and transverse coordinates, respectively, $\Omega$ is the dimensional vorticity and $M$ is the impulse of vorticity per unit density:

$$
M=\int_{-\infty}^{\infty} \mathrm{d} x \int_{0}^{\infty} \Omega r \mathrm{~d} r
$$

The corresponding stream function in this case can be written as follows $\left[{ }^{14}\right]$ :

$$
\Psi=-\frac{M}{4 \pi R_{0}}\left(\left(\mathrm{E}_{1}\left(s_{+}\right)+\ln \left(s_{+}\right)\right)-\left(\mathrm{E}_{1}\left(s_{-}\right)+\ln \left(s_{-}\right)\right),\right.
$$

where

$$
s_{ \pm}=\frac{1}{2}\left(\frac{\left(x-x_{0}\right)^{2}+\left(r \pm R_{0}\right)^{2}}{2 v t}\right)
$$

and

$$
\mathrm{E}_{1}=\int_{s}^{\infty} t^{-1} e^{-t} \mathrm{~d} t
$$

is the exponential integral function.

Equation (3) reasonably well approximates motion of the viscous vortex pair for all $\tau$. This assumption was earlier made by Rott and Cantwell $\left[{ }^{10}\right]$ when they developed the so called "heuristic model" of viscous vortex pairs. It is based on the fact that the Lamb-Oseen vortex solution satisfies both the Navier-Stokes equations (for non-zero $R e$ ) and the Stokes slow-flow equations (for $R e \rightarrow 0$ ). However, this fact is not valid for the superposition of these solutions, although solution (1)-(3) still satisfies the linear Stokes equations. The solution (1) is the plane analogue of the solution for the viscous vortex ring and represents two counter-rotating Lamb-Oseen vortices $\left[{ }^{17}\right]$. These vortices move with an average velocity $U_{t}$, which for the asymptotic drift stage (small value of $\left.\tau=R_{0} / \sqrt{2 v t}\right)$ is given by the equation $\left[{ }^{10}\right]$ : 


$$
U_{t}=\frac{\mathrm{d} x_{0}(t)}{\mathrm{d} t}=M /(32 \pi v t)=M \tau^{2} /\left(16 \pi R_{0}^{2}\right)
$$

In the limit $\tau \rightarrow \infty$, Eq. (3) reduces to the stream function in the form of two inviscid vortices with circulations $\pm \Gamma=M / R_{0}$, which are separated by a nominal distance $2 R_{0}$ in the $x$ direction. The translational velocity of this pair is $U_{t}=M /\left(4 \pi R_{0}^{2}\right)\left[{ }^{6}\right]$.

Introducing dimensionless variables $\sigma=r / R_{0}, \quad \eta=\left(x-x_{0}(t)\right) / R_{0}$, we can write

$$
s_{ \pm}=\frac{1}{2}\left(\eta^{2}+(\sigma \pm 1)^{2}\right) \tau^{2},
$$

and the stream function in the coordinate system, moving with the velocity $U_{t}$, can be presented as

$$
\Psi_{1}=-\frac{M}{4 \pi R_{0}}\left(\left(\mathrm{E}_{1}\left(s_{+}\right)+\ln \left(s_{+}\right)\right)-\left(\mathrm{E}_{1}\left(s_{-}\right)+\ln \left(s_{-}\right)\right)-U_{t} \sigma R_{0} .\right.
$$

The case, studied by Rom-Kedar et al. [ $\left.{ }^{6}\right]$, corresponds to the limit $\tau \rightarrow \infty$. A comparison of the stream function $\Psi$ for various values of $\tau$ with the result for the inviscid vortices $\left.{ }^{6}\right]$ in Fig. 2 illustrates this conclusion. For the rest of the present paper it is assumed that $\tau<1$.

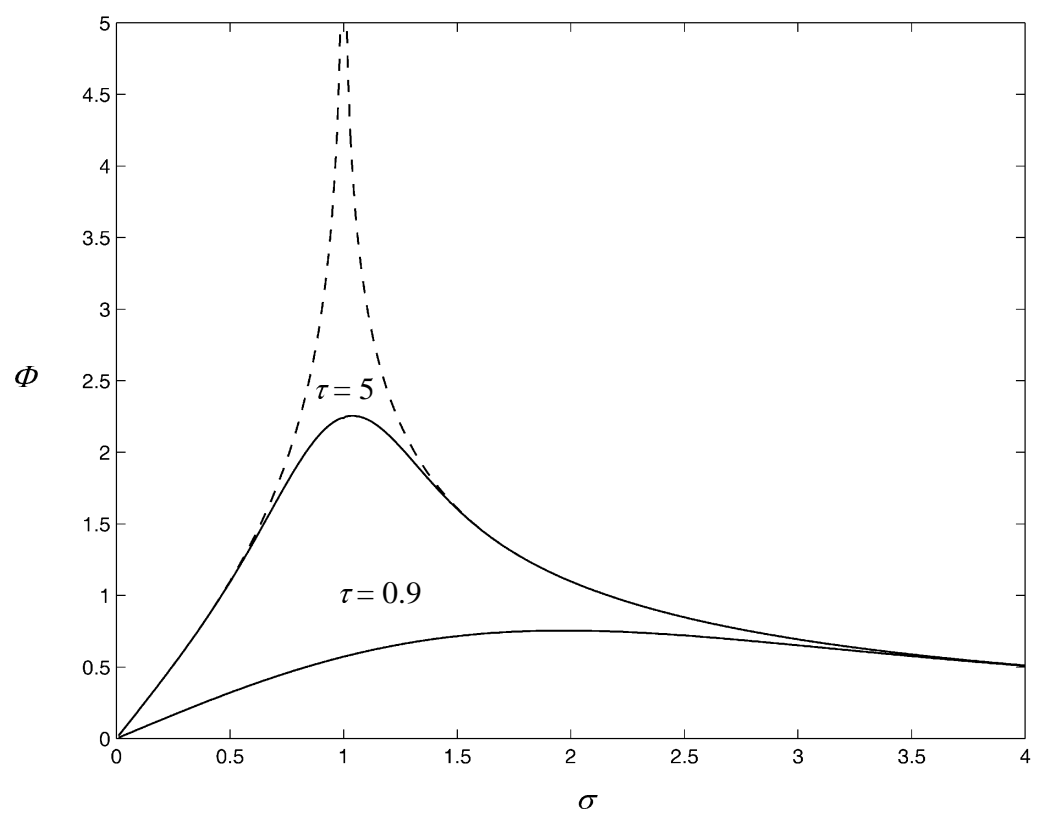

Fig. 2. Stream function profiles $\Phi=\Psi\left(2 \pi R_{0} / M\right)$, based on Eq. (3), for different values of $\tau$ (solid lines); dashed curve corresponds to the inviscid case. 


\section{OSCILLATING VISCOUS VORTEX PAIR}

We consider a flow, controlled by a viscous vortex pair in the presence of an oscillating external strain-rate field. In this case, the stream function in the coordinate system, moving with velocity $U_{t}$, can be written in the form $\left[{ }^{6}\right]$ :

$$
\Psi_{2}=-\frac{M}{4 \pi R_{0}}\left(\left(\mathrm{E}_{1}\left(s_{+}\right)+\ln \left(s_{+}\right)\right)-\left(\mathrm{E}_{1}\left(s_{-}\right)+\ln \left(s_{-}\right)\right)-U_{t} \sigma R_{0}+\varepsilon_{1} \sigma \eta R_{0}^{2} \sin (\omega t) .\right.
$$

The equations for the components of the flow velocity can be presented as

$$
\frac{\mathrm{d} x}{\mathrm{~d} t}=\frac{\partial \Psi_{2}}{\partial r}, \quad \frac{\mathrm{d} r}{\mathrm{~d} t}=-\frac{\partial \Psi_{2}}{\partial x} .
$$

To simplify the analysis, it is assumed that $\tau$ is fixed. Introducing new dimensionless variables

$$
\begin{gathered}
\varsigma=\Omega / \varsigma_{0}, \varsigma_{0}=M /\left(4 \pi v t R_{0}\right), \Phi_{2}=\Psi_{2} / \varsigma_{0} L^{2}=\Psi_{2}\left(2 \pi R_{0} / M\right), \quad s=M t / 2 \pi R_{0}^{3}, \\
\varepsilon=\varepsilon_{1} / \omega, \quad U=2 U_{t} \pi R_{0}^{2} / M, \quad \theta=\left(2 \pi \omega R_{0}^{3}\right) / M,
\end{gathered}
$$

the following equations for the fluid particle (passive scalar) locations are derived:

$$
\begin{gathered}
\frac{\mathrm{d} \eta}{\mathrm{d} s}=\frac{\partial \Phi_{2}}{\partial \sigma}=u-U+(\varepsilon \theta) \eta \sin (s \theta), \\
\frac{\mathrm{d} \sigma}{\mathrm{d} s}=-\frac{\partial \Phi_{2}}{\partial \eta}=v-(\varepsilon \theta) \sigma \sin (s \theta),
\end{gathered}
$$

where the normalized velocity components $u, v$ in the moving vortex pair can be presented as

$$
\begin{gathered}
u=\frac{\tau^{2}}{2}\left\{\frac{(\sigma-1)}{s_{-}}\left[\exp \left(-s_{-}\right)-1\right]-\frac{(\sigma+1)}{s_{+}}\left[\exp \left(-s_{+}\right)-1\right]\right\}, \\
v=\eta \frac{\tau^{2}}{2}\left\{\frac{1}{s_{+}}\left[\exp \left(-s_{+}\right)-1\right]-\frac{1}{s_{-}}\left[\exp \left(-s_{-}\right)-1\right]\right\} .
\end{gathered}
$$

Here $\varepsilon$ is the perturbation intensity (assumed to be small) and $\theta$ is the normalized perturbation frequency. Equations (8) and (9) are solved numerically using the standard fourth-order Runge-Kutta method. The calculations were performed for 20 points, located at $x_{i}=0, \quad r_{i}=0.03+0.03 \times(i-1)$ for 3000 periods of perturbation. The fixed time step $\Delta s$ was equal to $10^{-3}$. 
Poincaré sections were used for studies of time-dependent dynamical systems; sampling the fluid particle trajectories at time intervals equal to the period of perturbation was applied. This was achieved by introducing the function $\theta^{*}=\theta s$ and by obtaining the sections as

$$
\left(\sigma\left(\theta^{*}\right), \eta\left(\theta^{*}\right)\right) \rightarrow\left(\sigma\left(\theta^{*}+2 \pi\right), \eta\left(\theta^{*}+2 \pi\right)\right) .
$$

When the system is unperturbed, the fluid particles, initially located close to the centre of the vortex pair, are trapped there and move along closed-path streamlines around the pair centre. Figure 3 shows the Poincare section for a system that is slightly perturbed $\left(\varepsilon_{m}=\varepsilon \theta=0.001, \tau=0.9\right)$. This pattern is very close to the pattern of the unperturbed system. When $\varepsilon_{m}$ increases to 0.05 , particle trajectories become very irregular and chaotic. The well-known stochastic domain in the phase space appears (Fig. 4). Ottino $\left[^{7}\right]$ has shown that invariant orbits near the hyperbolic points under the influence of the perturbation can be destroyed and lead to the generation of stable and unstable manifolds. Their crossing indicates the presence of chaotic fluid particle motion.

Phase dynamics around the hyperbolic (saddle) points in the inviscid vortex pair was studied by Rom-Kedar et al. [ $\left.{ }^{6}\right]$. The asymptotic expansions for small $\varepsilon$ were used and the trajectories of the fluid particles were located very close to the two saddle points. One set was integrated forward in time, while the other was integrated backward in time to generate the stable and unstable manifolds,

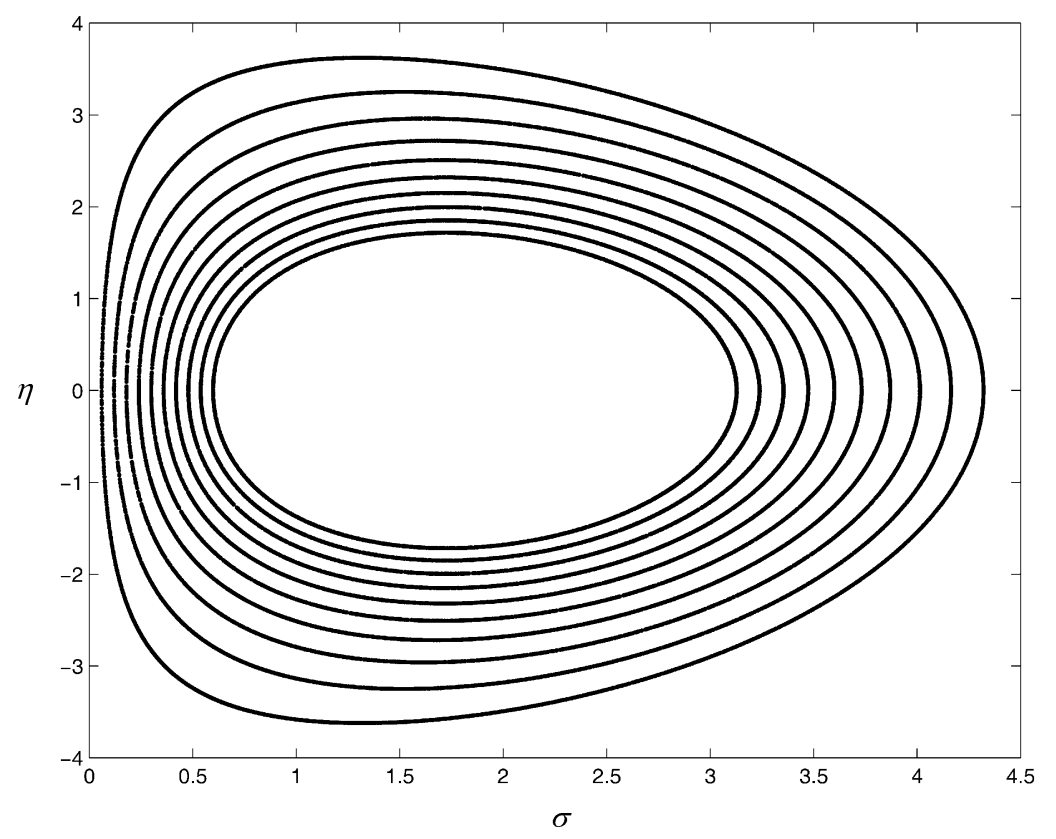

Fig. 3. Poincaré sections for system of Eqs. (8)-(9) with small perturbation constant $\varepsilon_{m}=0.001$ $(\tau=0.9)$. 


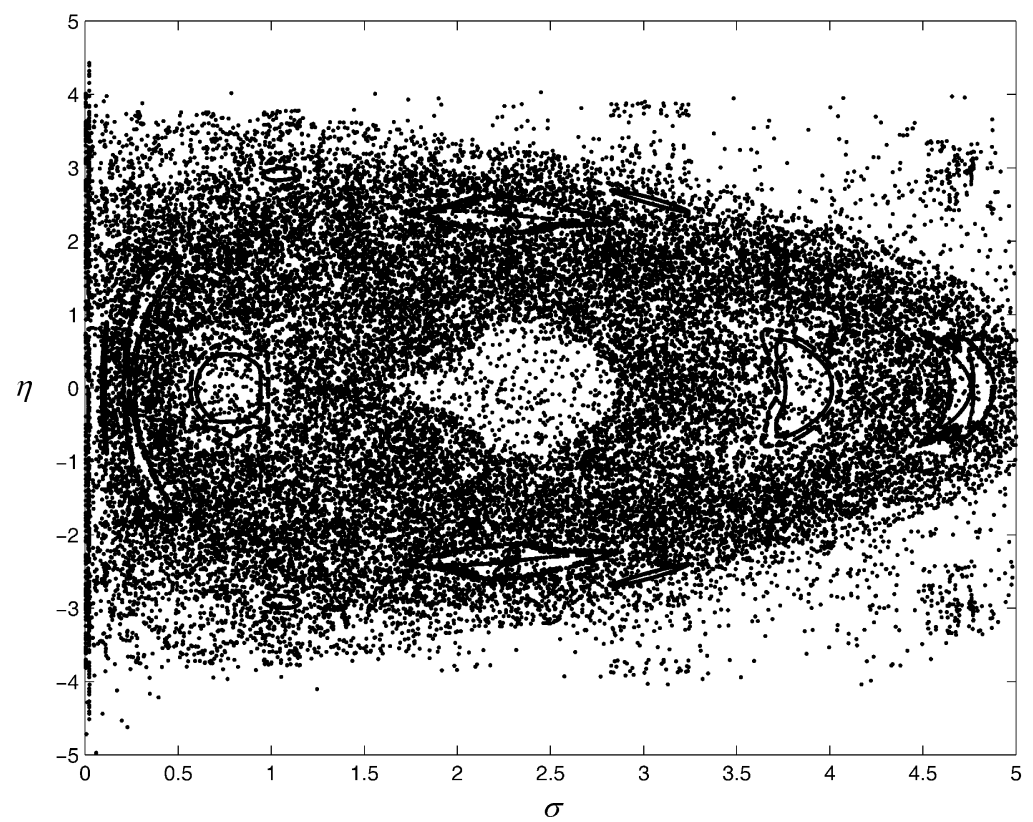

Fig. 4. Poincaré sections for the system of Eqs. (8)-(9) by perturbation frequency $\theta=0.33$ $\left(\varepsilon_{m}=0.05, \tau=0.9\right)$.

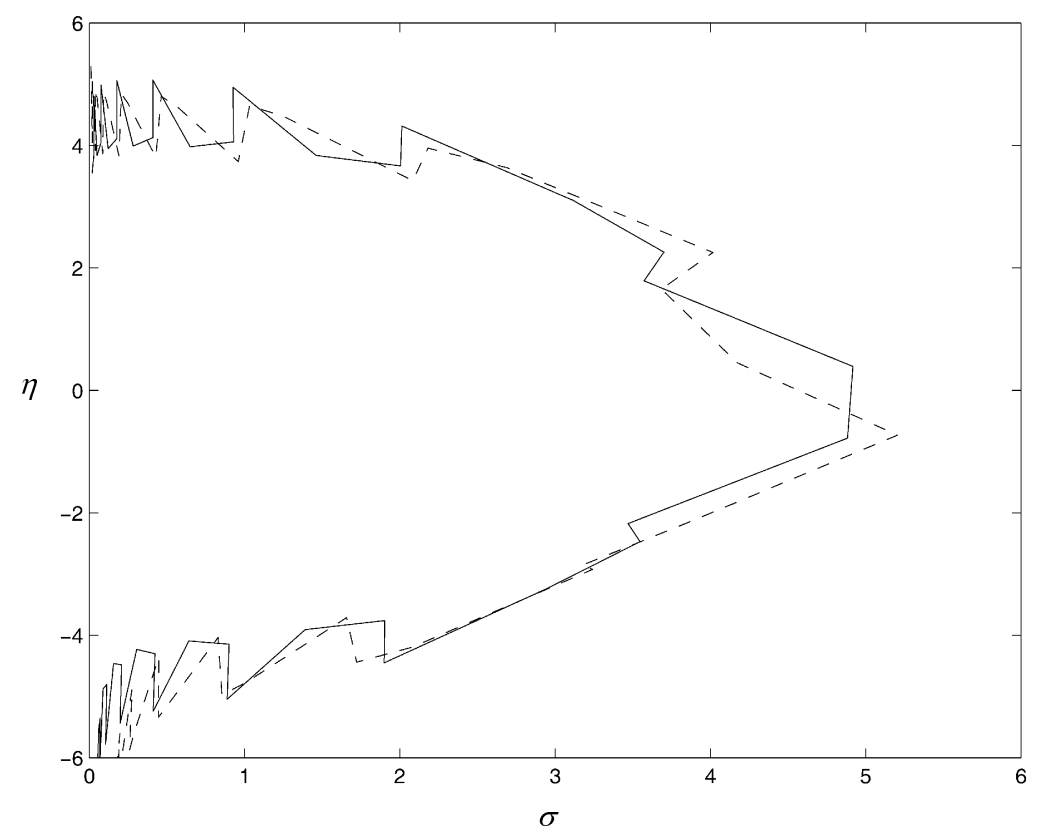

Fig. 5. A plot of stable and unstable manifolds for the system of Eqs. (8)-(9) by perturbation frequency $\theta=0.33$ with $\varepsilon_{m}=0.05$; the solid line represents the unstable manifold while the dashed line represents the stable one. 
respectively. As in this case the stable and unstable manifolds cross, they indicate the presence of chaos. Figure 5 shows the relevant plots, calculated on the basis of Eqs. (8)-(9), where the normalized perturbation frequency $\theta$ was taken equal to 0.33 for $\varepsilon_{m}=0.05$ with $\tau=0.9$. The saddle points were located at $(0,-4.5)$ and $(0,4.5)$. As can be seen from Fig. 5, stable and unstable manifolds cross and this confirms the presence of the chaotic fluid particle motion for a viscous vortex pair. Current predictions also show that this effect disappears for "fat" pairs when $\tau$ reduces to 0.7 .

As the normalized perturbation frequency increases above $\theta=0.33$ with $\varepsilon_{m}=0.05$, then small islands start to appear in the pattern. This pattern shows better organization and is transformed into invariant curves as the normalized perturbation frequency $\theta$ is increased to 1 (Fig. 6). Such invariant curves are referred to as KAM tori, after Kolmogorov, Arnol'd and Moser, who were the first to demonstrate this feature (the result is known as the KAM theorem) $\left[{ }^{18}\right]$. KAM curves represent total barriers to fluid motion, reducing mixing and transport. As the perturbation frequency is increased further, the Poincaré sections start to return to the earlier observed forms, characteristic for the unperturbed system (Fig. 7). This indicates that the perturbation frequency plays a significant role in the structure of the dynamical system, and mixing becomes most effective for relatively low perturbations frequencies.

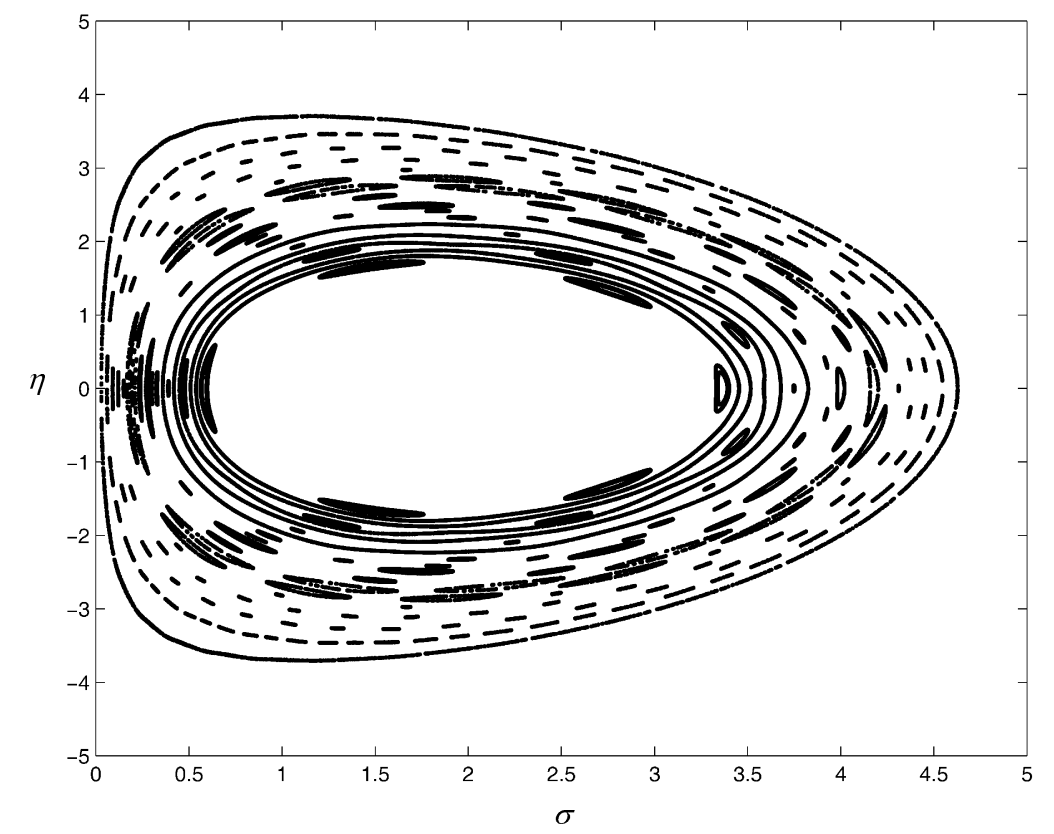

Fig. 6. Poincaré sections for the system of Eqs. (8)-(9) by perturbation frequency $\theta=1$ $\left(\varepsilon_{m}=0.05, \tau=0.9\right)$. 


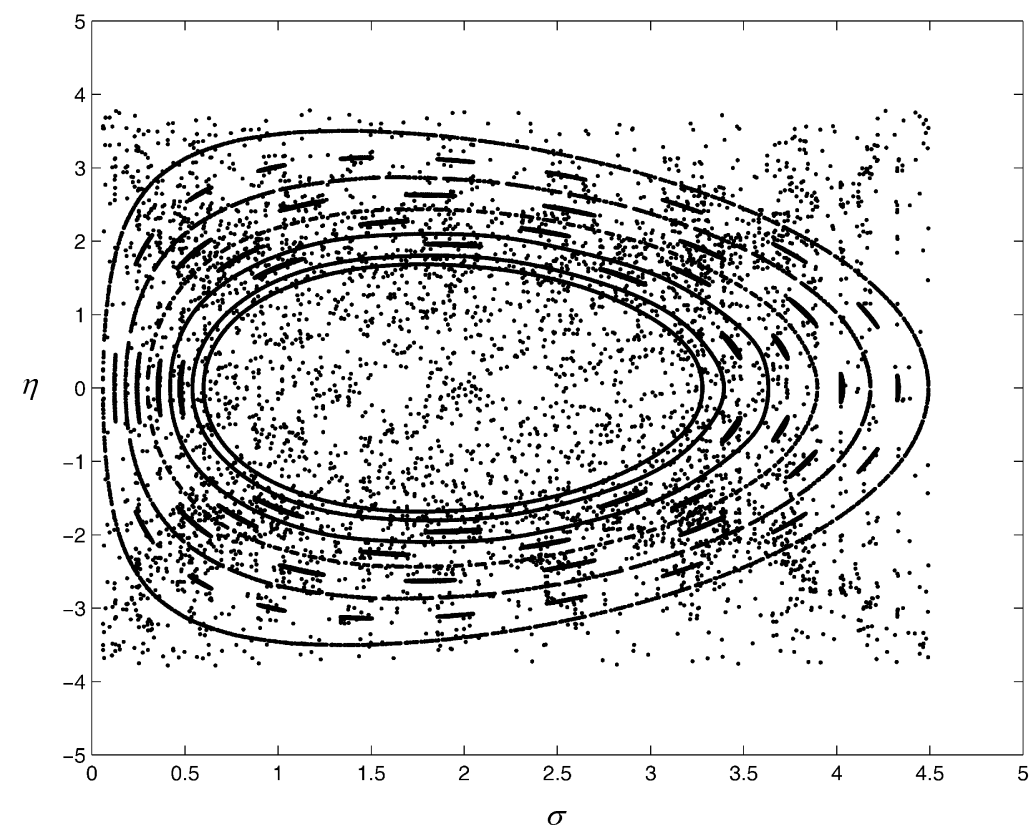

Fig. 7. Poincaré sections for the system of Eqs. (8)-(9) by perturbation frequency $\theta=1.3$ $\left(\varepsilon_{m}=0.05, \tau=0.9\right)$.

\section{DYNAMICS OF SMALL SPHERICAL PARTICLES}

The following assumptions are adopted concerning particles:

1) all particles are rigid spheres with constant densities,

2) inter-particle interactions are negligible,

3) the effect of the particles on the flow is negligible.

The equation of motion for a small rigid sphere in a non-uniform and unsteady flow field was derived by Maxey and Riley $\left[{ }^{19}\right]$. We will consider its corrected $\left[{ }^{20}\right]$ and simplified form, in which the Basset history term is ignored. The equations of motion of a small rigid sphere of diameter $d$ and mass $m_{p}$ can be presented as follows:

$$
m_{p} \frac{\mathrm{d} \mathbf{V}}{\mathrm{d} t}=m_{f} \frac{D \mathbf{u}}{D t}-\frac{1}{2} m_{f}\left(\frac{\mathrm{d} \mathbf{V}(t)}{\mathrm{d} t}-\frac{D \mathbf{u}}{D t}\right)-3 \pi \mathrm{d} \mu_{f}(\mathbf{V}(t)-\mathbf{u}[\mathbf{Y}(t), t]),
$$

where $D / D t$ indicates the Lagrangian derivative following a fluid element in the neighborhood of the particle, while $\mathrm{d} / \mathrm{d} t$ indicates the Lagrangian derivative following the moving particle, $\mathbf{Y}=(x, r)$ is the position vector, which shows the instanteneous location of the particle, $\mathbf{V}=(\mathrm{U}, \mathrm{V})$ is the velocity vector of the sphere, and $\mathbf{u}=(\mathrm{u}, \mathrm{v})$ is the velocity vector of the flow field, undisturbed by the presence of the sphere, $m_{f}$ is the mass of the fluid, displaced in the sphere and $\mu_{f}$ is the dynamic viscosity of the fluid. 
The following non-dimensional variables are introduced:

$$
\mathbf{x}^{*}=\mathbf{x} / R_{0}, \mathbf{u}^{*}=\mathbf{u} /\left(\varsigma_{0} R_{0}\right), \mathbf{U}^{*}=\mathbf{U} /\left(\varsigma_{0} R_{0}\right), t^{*}=t\left(\varsigma_{0}\right) .
$$

The dimensionless form of Eq. (12), omitting asterisks, is presented as $\left[{ }^{20,21}\right]$ :

$$
\frac{\mathrm{d} \mathbf{V}}{\mathrm{d} t}=\frac{3}{2} \delta\left(\frac{\partial \mathbf{u}}{\partial t}+\mathbf{u} \frac{\partial \mathbf{u}}{\partial \mathbf{x}}\right)-\frac{2}{S t}(\mathbf{V}-\mathbf{u})
$$

where $\delta=\rho_{f} /\left(\rho_{p}+0.5 \rho_{f}\right)$ is the fluid-to-particle density ratio, $S t=T_{p} / T_{f}$ is the Stokes number; $T_{p}=\left(m_{p}+0.5 m_{f}\right) /\left(3 \pi d \mu_{f}\right)$ and $T_{f}=\varsigma_{0}^{-1}$ are the characteristic time scales of the particle and the fluid, respectively.

In the spirit of Maxey, two ranges of the ratio $\rho_{f} / \rho_{p}$, referring to two different sets of physical conditions, are considered. The first of these is the "bubble range" $0<\rho_{p} / \rho_{f} \leq 2$, when the parameter $\delta$ increases continuously from 0.4 to 2.0. In the second range, known as the "aerosol range", $0 \leq \delta \leq 0.4$ $\left(\rho_{p} / \rho_{f} \geq 2\right)$. A fourth-order Runge-Kutta method was used to integrate Eq. (13) numerically with a fixed dimensionless time step of $10^{-3}$. For relatively small values of Stokes numbers $(S t<2)$ in the bubble range, particles were mainly accumulated near the centre of the vortex pair. In this case, the effect of fluid inertia prevails and any influence of the perturbation on particles trajectories is negligible. As expected, for the particles in the aerosol range the most important term is the one depending on the Stokes number. Following $\left[^{8}\right]$, we focus on $\delta=0.1$, which corresponds to density ratio of 10 (typical value for particles in gas flows). A slightly perturbed motion $\left(\varepsilon_{m}=0.001\right)$ and relatively strongly perturbed motion $\left(\varepsilon_{m}=0.1\right)$ of particles are considered. In the first case, our calculations confirmed that particle inertia produces a centrifugal effect, which moves them from the region, where the vorticity is strongest (vortex pair atmosphere) into the ambient flow. The situation changes when the influence of perturbations increases. Under these conditions, for $\varepsilon_{m}=0.1$ and $S t<10$, the particles initially located in the vortex pair region start to migrate between right and left vortices. A typical Poincaré section for a single particle migration is shown in Fig. 8. It is interesting to note that particle motion inside the region of the vortex pair flow can exist for a considerable time (at least up to $10^{3}$ periods of the perturbation). In this case, for $S t<10$ the effect of the perturbation compensates the centrifugal effect that causes shedding of the particles into the free flow, and the long-term accumulation of particles in the vortex pair region is observed.

The reported results are preliminary. A careful investigation is required to establish the range of applicability of the conclusions, reported in Section 3, to describe the dynamics of particles for practical applications. When applied to direct-injection petrol engines, the results reported may help to establish general trends of the processes and to understand the underlying physics, but not to provide a self-consistent model of the processes involved. First, the most likely observed configurations are vortex rings and not vortex pairs. Secondly, the time 


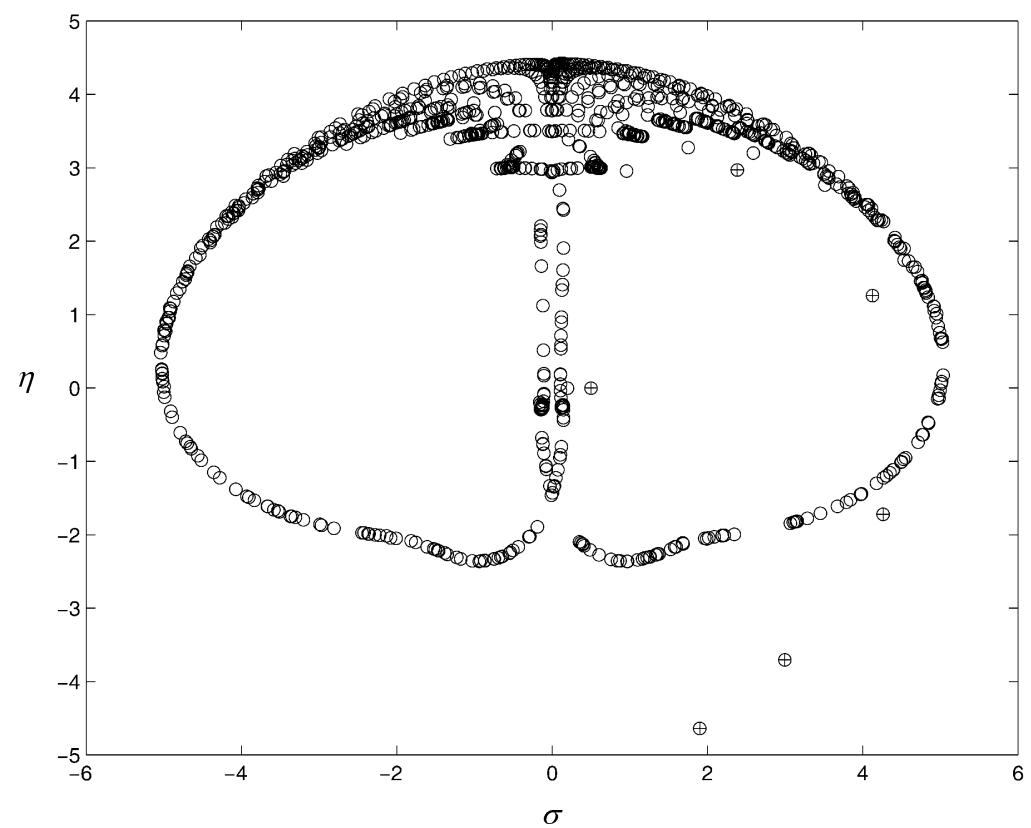

Fig. 8. Poincaré sections for a single aerosol particle, initially located at $(0.2,0)$ with $S t=8$ and $\delta=0.1$ by perturbation frequency $\theta=0.33\left(\varepsilon_{m}=0.1, \quad \tau=0.9\right)$; particle positions are sampled every period (based on the perturbation frequency) and are marked as "o"; particle positions for slightly perturbed motion $\left(\varepsilon_{m}=0.001\right)$ are marked as " $\oplus$ ".

scales involved are generally far too short to allow a proper chaotic configuration to be established. Thirdly, the analysis presented in this paper ignores a number of processes, which could significantly change the predicted behaviour of the system (e.g. the influence of particles on the flow, the asymmetric structure of the vortex ring, effects of external flows, etc.). Ideally, the methods used widely in modern computational dynamics codes would be expected to provide selfconsistent modelling of all these processes. Unfortunately this is not the case, as the models used are focused on the simultaneous analysis of numerous processes involved $\left[{ }^{22}\right]$. Hence, the models of individual processes are inevitably rather simplistic and many effects, such as those described by Eq. (12), are generally overlooked. Hence, despite the limitations of the models, considered in this paper, they are expected to complement effectively the results predicted by conventional CFD codes.

\section{SUMMARY}

Particle dynamics inside a vortex pair is described in terms of a relatively simple model, based on the solution of the Stokes equation and on the methodology reported in $\left[^{8}\right]$. The effects of external forces on the fluid flow have 
been considered. The perturbed flow has been studied using the viscous vortex pair model, the particle-path equations and well-established techniques, such as computing Poincare maps. It is shown that the fluid flow inside the viscous vortex pair in the range $0.7<\tau<1$ can display Lagrangian chaos when the pair is under the influence of a periodic perturbation. This chaos is associated with better mixing and transport of particles. However, an increase of the perturbation frequency causes the appearance of regions where bounded quasi-periodic motion occurs (known as the KAM tori). These regions represent barriers to fluid motion, thus limiting the transport of particles.

A similar periodic perturbation is shown to change the Lagrangian dynamics of small spherical particles, inserted into the viscous vortex pair flow. The influence of this perturbation can improve mixing and transport of the aerosol particles for a certain range of particle parameters $(S t<10, \delta=0.1)$ via preventing their penetration into the free flow. The results can be used to study the trends in droplet transport and mixing occurring in spray combustors (e.g. direct-injection gasoline engines), complementing the results predicted by conventional computational fluid dynamics codes.

\section{ACKNOWLEDGEMENTS}

Authors would like to thank Prof. Y. A. Sergeev (University of Newcastle) for helpful discussions. This work was supported by Estonian Ministry of Education and Science (Project No. 0812526S03).

\section{REFERENCES}

1. Aref, H. Integrable, chaotic and turbulent vortex motion in two-dimensional flows. Ann. Rev. Fluid Mech., 1983, 15, 345-368.

2. Aref, H. Stirring by chaotic advection. J. Fluid Mech., 1984, 143, 1-21.

3. Aref, H. and Balachandar, S. Chaotic advection in Stokes flow. Phys. Fluids, 1986, 29, 35153521.

4. Ottino, J. The Kinematics of Mixing: Stretching, Chaos and Transport. Cambridge University Press, Cambridge, 1989.

5. Sazhin, S. S., Kaplanski, F., Feng, G., Heikal, M. R. and Bowen, P. J. A fuel spray induced vortex ring. Fuel, 2001, 80, 1871-1883.

6. Rom-Kedar, V., Leonard, A. and Wiggins, S. Transport, mixing and chaos in an unsteady vortical flow. J. Fluid Mech., 1990, 214, 347-394.

7. Ottino, J. M. The mixing of fluids. Sci. Amer., 1989, 260, 56-67.

8. Tsega, Y., Michaelides, E. E. and Eschenazi, E. V. Particle dynamics and mixing in the frequency driven 'Kelvin cat eyes' flow. Chaos, 2001, 11, 351-358.

9. Phillips, O. M. The final period of decay of non-homogeneous turbulence. Proc. Cambridge Philos. Soc., 1956, 52, Pt. 1, 135-151.

10. Rott, N. and Cantwell, B. Decay of a viscous vortex pair. Phys. Fluids, 1988, 31, 3213-3224.

11. Kambe, T. and Oshima, Y. Generation and decay of viscous vortex rings. J. Phys. Soc. Jap., $1975,38,271-280$. 
12. Kaltaev, A. Investigation of dynamic characteristics of motion of a vortex ring of viscous fluid. In Continuum Dynamics. Kazakh State University. Alma-Ata, 1982, 63-70 (in Russian).

13. Kaplanski, F. On the diffusion of the circular vortex filament. Izv. Akad. Nauk Est. SSR, Fiz. Mat., 1984, 33, 372-374 (in Russian).

14. Berezovski, A. and Kaplanski, F. Diffusion of a ring vortex, Fluid Dynamics, 1988, 22, 832836, Plenum Publ., translated from Izvestiya Akademii Nauk USSR, Mekhanika Zhidkosti i Gasa, 1987, 6, 10-15.

15. Berezovski, A. and Kaplanski, F. Vorticity distributions for thick and thin vortex pairs and rings. Arch. Mech., 1995, 47, 1015-1026.

16. Kaplanski, F. and Rudi, U. Dynamics of a viscous vortex ring. Int. J. Fluid Mech. Res., 1999, 26, 618-630.

17. Lamb, H. Hydrodynamics (6th ed.) Dover, New York, Secs. 150 and 152, 1932.

18. Guckenheimer, J. and Holmes, P. Nonlinear Oscillations, Dynamical Systems, and Bifurcations of Vector Fields. Springer-Verlag, New York, 1983.

19. Maxey, M. R. and Riley, J. J. Equation of motion for small rigid sphere in a nonuniform flow. Phys. Fluids, 1983, 26, 883-889.

20. Coimbra, C. F. M. and Kobayashi, M. H. On the viscous motion of a small particle in a rotating cylinder. J. Fluid Mech., 2002, 469, 257-286.

21. Maxey, M. R. The motion of small spherical particles in a cellular flow field. Phys. Fluids, 1987, 30, 1915-1925.

22. Sazhina, E. M., Sazhin, S. S., Heikal, M. R., Babushok, V. I. and Johns, R. A detailed modelling of the spray ignition process in Diesel engines. Combust. Sci. Technol., 2000, 160, $317-344$.

\title{
Osakeste dünaamika ja segunemine võnkuvas viskoosses keerispaaris
}

\author{
Felix Kaplanski, Sergei Sazhin ja Ülo Rudi
}

Stokesi lahendusel baseeruvat viskoosse keerispaari (VKP) mudelit rakendatakse osakeste dünaamika ja segunemise uurimiseks keerisrõngataolistes struktuurides. Eeldatakse, et perioodilise häiritusega vooluväljas asuvad väikesed sfäärilised osakesed. Häiritud vooluse uurimiseks kasutatakse VKP mudelit, osakeste trajektoori võrrandeid ja kohandatud Poincaré kaartide meetodit. Näidatakse, et voolamine keerise sees võib osutuda kaootiliseks, kui suhteliselt paksule keerisrõngale (st keerise läbimõõt on võrreldav rõnga raadiusega) mõjub perioodiline häiritus. Sel juhul eeldatakse, et ka segunemistingimused on parimad. Samas põhjustab häirituse sageduse suurendamine "piiratud kvaasiperioodilise liikumisega" piirkondade tekke. Need piirkonnad käituvad faasiruumis segunemisprotsessi ja transporti pärssivate barjääridena. Häirituse sissetoomine põhjustab sfääriliste aerosool-tüüpi osakeste trajektooride muutumise. Keerise sees täheldatakse osakeste akumuleerumist kindlas Stokesi kriteeriumi väärtuste vahemikus $(S t<10)$, samal ajal kui häirituse puudumisel kanduvad need osakesed keerisest välja ümbritsevasse voolusesse. 